\title{
O PROTAGONISMO INDÍGENA NAS AULAS DE HISTÓRIA: PROBLEMAS E DESAFIOS NO LIVRO DIDÁTICO
}

\author{
THE INDIGENOUS PROTAGONISM IN THE CLASSES OF HISTORY: PROBLEMS \\ AND CHALLENGES IN THE TEXTBOOK
}

Francis Mary Soares C. da Rosa ${ }^{1}$

\begin{abstract}
RESUMO: Objetivamos nesse artigo um estudo ensaístico das possibilidades de implementação da lei $11.645 / 08$ no que se refere à temática indígena nas aulas de História da Educação Básica, por meio de um estudo crítico ao livro didático de História e das categorias de análise presente na História Indígena, a saber, resistência e protagonismo. A escolha pelos conceitos de protagonismo e resistência indígena como fio condutor surge diante de uma dupla necessidade enquanto professora, historiadora e filósofa: o primeiro passo é construir um viés crítico à imagem dos povos indígenas em um dos livros didáticos de História aprovados no último PNLD/História-2018, historicizando as categorias de análise costumeiramente apresentadas, e o segundo passo: estabelecer subsídios para se pensar criticamente a produção de um "vazio" discursivo no que se refere ao protagonismo e os movimentos de luta e resistência indígenas. Por meio de uma revisão bibliográfica crítica e relacional ao tema, optou-se por uma abordagem ensaística, porém fundamentada em uma revisão da literatura que aponta como principal suporte os estudos de Grupioni (2004), Munduruku (2009, 2012) e Santos e Felipe (2016), dentro outros. Espera-se contribuir para a ampliação sobre as discussões da implementação da Lei 11.645/08 e o livro didático de História, assim como apontar subsídios para o Ensino de História comprometido com essa demanda legal.
\end{abstract}

Palavras-chave: Lei 11.645/08. Livro didático. Ensino de história. Protagonismo indígena.

ABSTRACT: In this article, we present an essay study of the possibilities for the implementation of Law 11.645 / 08 regarding indigenous issues in the History of Basic Education, through a critical study of the textbook of History and of the categories of analysis present in Indigenous History, namely, resistance and protagonism. The choice of the concept of indigenous protagonism and resistance as a guiding thread arises in the face of a double need as a teacher, historian and philosopher: the first step is to construct a critical bias to the image of indigenous peoples in one of the history textbooks approved in the last PNLD / History-2018, historicizing the categories of analysis customarily presented and, the second step: to establish subsidies to think critically the production of a discursive "void" in relation to the protagonism and movements of indigenous struggle and resistance. Through a critical and relational bibliographical revision of the theme, we opted for an essay-based approach, but based on a literature review that points to the studies of Grupioni (2004), Munduruku (2009,

\footnotetext{
${ }^{1}$ Doutoranda em Educação (PPGEduc- Uneb), professora efetiva do Instituto Federal de Educação Baiano- IF Baiano, campus Xique-Xique.
} 
2012) and Santos and Felipe (2016), in others. It is hoped to contribute to the expansion on the discussions of the implementation of law 11.645 / 08 and the textbook of history, as well as to point out subsidies for the teaching of history committed to this legal demand.

Keywords: Law 11.645/08. Textbook. Teaching history. Indigenous protagonism.

\section{Introdução}

"Então, é assim que se cria uma única história: mostre um povo como uma coisa, como somente uma coisa, repetidamente, e será o que eles se tornarão." Chimamanda Ngozi Adichie (2009)

Ao longo dos quase dez anos da promulgação da Lei $11.645 / 2008^{2}$, de 10 de março de 2008, que alterou a Lei $10.639 / 2003^{3}$ de 9 de janeiro de 2003, se observa um tímido avanço em relação ao atendimento dessa demanda legal nas instituições de ensino da Educação Básica. A lei 11.645/2008 torna obrigatório o estudo da História e Cultura Africana, Afro-Brasileira e Indígena, tal como descrito em seu artigo 26-A:

Art. 26-A. Nos estabelecimentos de ensino fundamental e de ensino médio, públicos e privados, torna-se obrigatório o estudo da história e cultura afro-brasileira e indígena. § 10 O conteúdo programático a que se refere este artigo incluirá diversos aspectos da história e da cultura que caracterizam a formação da população brasileira, a partir desses dois grupos étnicos, tais como o estudo da história da África e dos africanos, a luta dos negros e dos povos indígenas no Brasil, a cultura negra e indígena brasileira e o negro e o índio na formação da sociedade nacional, resgatando as suas contribuições nas áreas social, econômica e política, pertinentes à história do Brasil. § 20 Os conteúdos referentes à história e cultura afro-brasileira e dos povos indígenas brasileiros serão ministrados no âmbito de todo o currículo escolar, em especial nas áreas de educação artística e de literatura e história brasileiras (BRASIL, 2008).

Especificamente no cenário baiano, tendo como fonte pesquisas nos repositórios dos programas de pós-graduação em Educação da UFBA e da UNEB

${ }^{2}$ A Lei 11.645/2008 diz respeito à obrigatoriedade da temática História e Cultura Africana, AfroBrasileira e Indígena nos currículos escolares. (BRASIL, 2008)

${ }^{3}$ A referida Lei altera a Lei n. 0 9.394, de 20 de dezembro de 1996, que estabelece as Diretrizes e Bases da Educação Nacional, para incluir no currículo oficial da Rede de Ensino a obrigatoriedade da temática História e Cultura Africana e Afro-brasileira.

História \& Ensino, Londrina, v. 25, n. 1, p. 203-226, jan./jun. 2019 
entre os anos 2009-2016, há poucos estudos que se aprofundam em mensurar e apontar o que de fato foi, efetivamente, concretizado nos currículos das instituições da Educação Básica baianas estaduais, municipais e da rede privada.

Uma pesquisa desenvolvida pelo Laboratório de Análises Econômicas, Históricas, Sociais e Estatísticas das Relações Raciais (LAESER) (TEMPO EM CURSO, 2013) do Instituto de Economia (IE) da UFRJ, tendo como base a Prova Brasil de 2009, constatou que somente sete em cada dez escolas públicas do Ensino Fundamental estariam adotando ações integrais ou isoladas no que concerne ao atendimento no disposto da Lei no currículo das instituições de ensino analisadas. Os estados das regiões Nordeste $(60,2 \%)$ e Norte $(56,4 \%)$ estavam entre os últimos com taxas de aplicação. Algumas dissertações e estudos ${ }^{4}$ apontam avanços e dificuldades na implementação, apostando como tema central a análise no que se refere a Lei $10.639 / 2003^{5}$. Timidamente vão ocorrendo pesquisas que propõem como objetivo central avaliar a aplicabilidade da Lei 11.645/2008 na Bahia, no que diz respeito à História Indígena, embora já exista alguns estudos que direcionam suas preocupações no que concerne ao atendimento da Lei $10.639 / 2003$ no estado baiano. Em tese de doutorado sobre a implementação da lei 10.639/03 na Bahia, Borges conclui:

[...] é a falta de ação planejada e sistematizada do Estado para a inserção dos estudos africanos nos currículos da Educação Básica o elemento decisivo da precária existência desses conteúdos nas escolas baianas. Desse modo, a tríade resistência, formação/conhecimento e ação do poder público se retroalimentam como obstáculos para uma inserção apropriada dos estudos africanos na Educação Básica (BORGES, 2014, p. 298).

Podemos associar tais fatores que dificultam o pleno atendimento do estudo da História e Cultura Africana e Afro-Brasileira ao desenvolvimento e implementação da Lei 11.645/08, no que concerne à História Indígena, visto que a ausência da formação continuada, a lacuna na grade disciplinar nos cursos

\footnotetext{
${ }^{4}$ Tais afirmações são corroboradas pela pesquisa utilizando palavras-chave nos principais repositórios de monografias, dissertações e teses da UFBA, UNEB, UFRB, UFOB.

${ }^{5}$ Por questões didáticas, políticas e atendendo, talvez, a especificidade das temáticas, há uma espécie de distinção no que se refere ao ensino de História e Cultura Afro-Brasileira e Africana, notadamente delimitado como Lei 10.639, e História e Cultura Indígena, notadamente delimitado como Lei 11.645.
} 
superiores de formação de professores, e o vazio das políticas públicas, podem ser evidenciados por qualquer professor ou professora da rede estadual baiana. Independentemente de estatísticas empíricas, o cumprimento da Lei 11.645/08 é uma tarefa em construção e os indícios demonstram um cenário de dificuldades.

Contudo, é necessário articular possibilidades de ações pedagógicas que fujam da abordagem circunstancial ou por projetos pedagógicos. O problema das abordagens supracitadas recai na continuidade e reprodução de estereótipos como o viés do exotismo, a visão caricatural e homogeneizadora dos povos originários do Brasil. A temática indígena não deve ser vivenciada como algo pontual e alocado em evento ou em um dia no calendário escolar, como o 19 de abril, por exemplo. As histórias e culturas (no plural) dos povos originários devem ser tratados como parte integrante de todo currículo escolar. Mesmo que no artigo $26-\mathrm{A}^{6}$, da referida Lei, haja uma indicação de especial atenção às áreas de Literatura, Artes e História, é sempre interessante apontar estratégias transdisciplinares na elaboração dos procedimentos pedagógicos em todas às áreas de conhecimento.

Nesse sentido, caminhamos para a proposta fulcral deste artigo, a saber, apontar contribuições à implementação da Lei $11.645 / 2008$ no que se refere à temática indígena no cenário baiano, tendo como ponto central o estudo da categoria conceitual da resistência e protagonismo indígena nas aulas de História. A escolha pelo conceito do protagonismo e resistência indígena como fio condutor surge diante de uma dupla necessidade enquanto professora, historiadora e filósofa: o primeiro passo é construir um viés crítico à imagem dos povos indígenas em um $^{7}$ dos livros didáticos de História aprovados no último PNLD/História-2018, historicizando as categorias de análise costumeiramente apresentadas e, o segundo passo: estabelecer subsídios para se pensar criticamente a produção de um "vazio" discursivo no que se refere ao protagonismo e os movimentos de luta e resistência indígenas. Acredito que tais

\footnotetext{
6 "Os conteúdos referentes à História e Cultura Africana, afro-brasileira e dos povos indígenas brasileiros serão ministrados no âmbito de todo o currículo escolar, em especial nas áreas de educação artística e de literatura e história brasileiras" (BRASIL, 2008).

${ }^{7}$ A escolha de apenas um dos livros, entre os 13 aprovados no último PNLD de História (2018) se justifica por dois fatores: primeiramente, o limite e os propósitos desse artigo e, em segundo aspecto, o livro analisado corresponde ao escolhido pelo corpo docente da unidade de ensino em que desenvolvo minhas atividades como regente de classe.
} 
movimentos ensaísticos são passos desobedientes e contrários na reprodução de um discurso pedagógico que insiste em essencializar os sujeitos históricos indígenas e marginalizá-los em uma eterna construção imagético-discursiva caricatural e a-histórica.

\section{A imagem dos povos originários em um livro didático: presentes, porém ainda invisíveis}

Daniel Munduruku (2009), tematiza em seus escritos que é sempre curioso como a ideia da indianidade e suas pertenças no Brasil sempre é defendida, quase como uma homogeneidade, com frases como "os índios são verdadeiros donos da terra"; "todos somos descendentes dos índios", dentre outras, construindo todo um repertório de frases prontas.

Em um primeiro plano, tais frases poderiam garantir a um hipotético transeunte que desconhece as dificuldades de reconhecimento da socio diversidade brasileira, a visão de uma certa respeitabilidade e legitimidade na presença de grupos étnicos distintos e diversificados dos povos originários no cenário nacional. Porém, se esse mesmo hipotético transeunte folhear um livro didático de História e tivesse que responder algumas questões sobre a diversidade e historicidade dos povos originários do Brasil, possivelmente teria como resposta a construção de um estereótipo vago e impreciso, visões arbitrárias e generalizantes, talvez até um sentimento fantasmagórico de presença fortuita e aparições esporádicas dentro de um contexto histórico eurocêntrico.

Os manuais didáticos possuem um papel fundamental na formação do imaginário das crianças e adolescentes em todas as etapas da fase de escolarização, além de contribuírem, de forma pontual, como arsenal instrumental no planejamento e construção dos planos de curso das escolas e docentes. Segundo Grupioni (2004), o livro didático desempenha um papel crucial no processo de formação da imagem que construímos das outridades. Muitas vezes, para uma maioria em idade escolar, ele representa a única fonte 
de informação e se constitui como único material impresso didático para discentes e, até mesmo, dos docentes.

Não somente no Ensino Médio, mas no Ensino Fundamental se observa a reprodução de estereótipos que reproduzem visões tais como selvagens, incivilizados, bárbaros e canibais. De acordo com Munduruku (2009, p. 21) os livros didáticos, em sua maioria, "[...] trazem uma imagem estereotipada: os nativos são sempre apresentados como seres que vivem nus, nas matas, habitando em ocas ou tabas e que cultuam diversos deuses, entre os quais Tupã. " Por mais que atualmente, e desde 2008, o Programa Nacional do Livro para Ensino Médio -PNLEM/2008 - adote como critério eliminatório obras que não atendam ao disposto e em consonância com as determinações da Lei 11.645/2008, observa-se, ainda, uma tímida presença que não se distanciou completamente de uma imagem pautada pelo exotismo, com categorias conceituais eventualmente equivocadas como "descoberta", e o tratamento da indianidade e das culturas indígenas como algo homogêneo. Como, por exemplo, a própria resenha oferecida de um dos treze livros didáticos de História aprovados no PNLD/2018:

As temáticas da História e da cultura da África, dos afro-brasileiros e dos povos indígenas, são apresentadas em capítulos especialmente destacados, em consonância com a opção teóricometodológica da obra. Observa-se que, nos volumes, estimula-se o convívio social e o reconhecimento da diferença. Na coleção se disponibiliza material para a exploração do tópico das relações étnico-raciais, do preconceito, da discriminação racial e da violência correlata, principalmente a partir da contextualização das origens das práticas discriminatórias, do estudo de biografias que retratam personagens negros em sua complexidade $e$ protagonismo social e histórico das lideranças e dos movimentos sociais antirracistas. O tema da História e cultura indígenas é contemplado ao longo da obra, indicando práticas de resistência indígena na época colonial, em uma abordagem atualizada (BRASIL, 2017, p. 43. grifo nosso).

Tendo como pressuposto a resenha supracitada do livro escolhido em minha unidade de ensino estadual, a saber, a coleção "História", da editora Saraiva, assinada por Georgina dos Santos, Jorge Ferreira, Ronaldo Vainfas e Sheila de Castro Faria, mas, sobretudo, tomando por base minha própria experiência com as obras aprovadas se pode observar, no que concerne à 
temática indígena, a abordagem da História dos povos originários eventualmente pelo viés eurocêntrico, tendo como ponto de partida o projeto colonizador. Cabe a pergunta: a historicidade dos povos originários somente ocorre pelo contato com as civilizações europeias? Para Grupioni (2004), esse tipo de abordagem centra-se na visão eurocêntrica da História, nos feitos das "potências" europeias, deslegitimando ou deixando para escanteio a problematização da perspectiva histórica dos povos originários, assim como relega esses sujeitos históricos às categorias secundárias.

A obra resenhada, a qual faz referência a citação acima, apresenta ao discente no capítulo dezessete, uma abordagem pouco crítica sobre o processo de "colonização" (ou "invasão", pois em diversas obras literárias e históricas escritas por indígenas e não indígenas o termo é severamente questionado, como, por exemplo: O banquete dos deuses de Daniel Munduruku, Esta terra tinha dono e Terra à vista descobrimento ou invasão de Benedito Prezia; e $A$ Terra dos mil povos de Kaka Werá).

A falta de criticidade repousa justamente na apresentação unilateral da perspectiva histórica: todo o processo de escrita e apresentação dos povos originários é mediado pelo ponto de vista eurocêntrico. Nos capítulos 9 e 17, únicos em que há destaque para uma incipiente História Indígena, em muitos trechos os povos originários são descritos com o termo genérico "indígenas", ou mesmo no singular. Aparecem de súbito e desaparecem ao final de alguns trechos. Há um esforço de questionar ou apontar subsídios para uma revisão histórica e conceitual de termos amplamente criticados pela comunidade historiográfica centrada nos estudos das histórias indígenas (ou como é conhecida a linha da "Nova história indígena") como "aculturação", "índio" e a vitimização dos povos originários, sobretudo no material de apoio ao professor.

Porém, no texto apresentado aos estudantes e imagens de apoio ainda nos deparamos com um viés que não historiciza, tampouco questiona as classificações étnicas e a diversidade dos povos originários. Na imagem abaixo, observe o quadro de abertura com a reprodução do quadro de Victor Meirelles, intitulado A primeira missa no Brasil. 
Figura 1 - Reprodução do quadro A primeira missa no Brasil oriunda do livro de didático

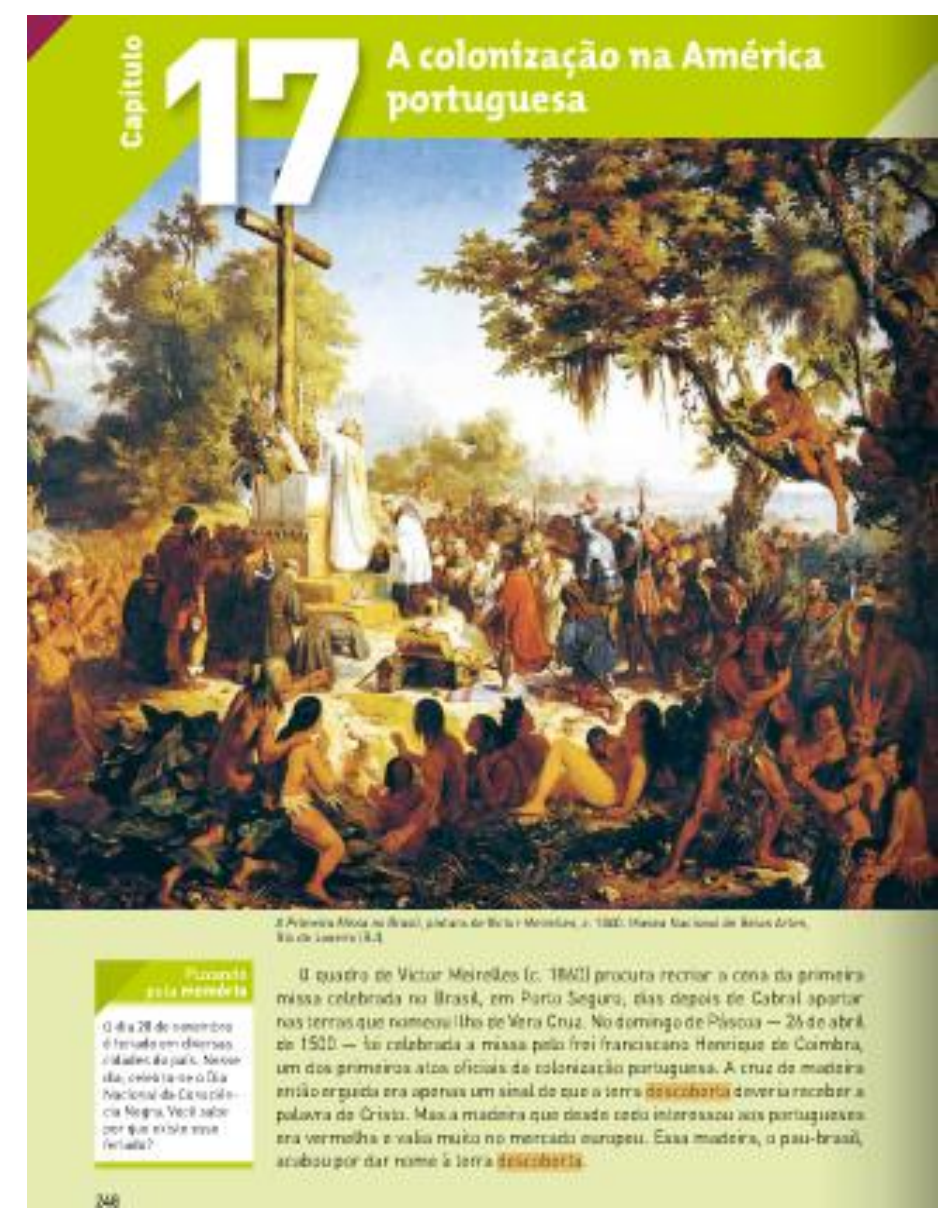

Fonte: VAINFAS et al. (2016, p. 248)

A descrição no quadro explicativo da figura é a seguinte: 
A cruz de madeira então erguida era apenas um sinal de que a terra descoberta deveria receber a palavra de Cristo. Mas a madeira que desde cedo interessou aos portugueses era vermelha e valia muito no mercado europeu. Essa madeira, o pau-brasil, acabou por dar nome à terra descoberta (VAINFAS et al., 2016, p. 248. Grifo nosso).

Ora, caracterizar o processo de chegada dos europeus como "descoberta" só ganha sentido se tomarmos como ponto de partida a visão histórica europeia. Tal perspectiva descaracteriza e invisibiliza toda uma dinâmica própria e mesmo anterior do continente batizado de "América" pelos europeus. Colocar como centro o continente europeu perpetua na formação discente a imagem e o discurso que corroboram com uma hierarquia de valores ao pontuar somente a visão europeia sobre a dinamicidade histórica. Não se destaca perspectivas críticas que eventualmente circundam o choque violento e desestabilizador das culturas originárias, como tematiza Dussel (1993), que colonizou alteridades. Para este autor, essa sobreposição de valores na escrita da História revela, por sua vez, o encobrimento de uma outridade por meio de uma incursão discursiva na criação e constituição sígnica da própria ideia de civilização: "A América não é descoberta como uma cultura distinta, como o Outro, mas como a matéria onde é projetado 'o si-mesmo' europeu. Então não é o 'aparecimento do Outro', mas a 'projeção do si - mesmo': encobrimento" (DUSSEL, 1993, p. 35).

Trata-se de tematizar no livro didático que os fatos históricos possuem interpretações e perspectivas sígnicas diferenciadas para todos os envolvidos. Não há uma versão "verdadeira" a ser ensinada, mas é preciso ficar atento que continuar com uma visão unilateral e sem pluriversalidade reproduz e estigmatiza uma imagem a-histórica dos povos originários. Hoje, mais do que em qualquer período, é possível trabalhar com fontes orais indígenas, literatura escrita por esses povos e uma vasta produção de historiadores e historiadoras indígenas e não-indígenas sobre o tema, entre outras fontes ${ }^{8}$. Essa atividade correlacional e transdisciplinar permite construir uma visão intercultural da

\footnotetext{
${ }^{8}$ Sobre o tema, o leitor pode ver a coleção "Índios na visão dos índios", organizado pela fundação Thydêwá, que conta com trabalhos assinados por vários grupos étnicos indígenas do Brasil. Além do livro autoral de Kaka JECUPÉ: A terra dos mil povos: história indígena brasileira contada por um índio. Editora Peirópolis, 1998. As obras de Daniel Munduruku e Olívio Jekupé também oferecem visões históricas, por meio do diálogo com literatura, um importante apoio didático.
} 
interpretação e construção no discurso histórico. E, nesse caso específico, também é uma postura combativa ao discurso de extinção que apregoa aos grupos indígenas a imagem de "seres" do passado que não dialogam com quaisquer futuros. De acordo com Michel Foucault (2013), o discurso não é somente a materialidade das relações de poder, mas, também, é a própria luta pelo poder, pelo espaço e pela legitimidade da fala. E eu acrescentaria pelo direito à memória e representatividade.

Ao desconsiderar a visão dos muitos povos originários sobre os fatos considerados históricos nos livros didáticos, reduzimos a perspectiva sobre a interpretação histórica, bem como sobre a experiência de vários povos, a somente uma única visão. Tal raciocínio também se estende às próprias imagens e fontes documentais que introduzem os discentes à uma incipiente História indígena nos manuais didáticos. Para Grupioni (2004), a utilização de imagens descontextualizadas, fragmentárias como as produzidas por cronistas, viajantes, oriundas dos primeiros séculos de colonização, dentre outras, são tomadas como evidências do "exotismo" dos povos originários e contribuem para uma leitura que organiza a existência desses povos somente em um passado distante e incompreensível para a contemporaneidade. Pode ser associado a isto, a estrutura descritiva e a utilização de verbos sempre no passado ao longo da escrita do texto.

Figura 2 - imagem retirada do livro de história analisado

\footnotetext{
$\mathrm{Na}$ faixa litorânea que veio a ser ocupada primeiramente pelos portugueses, prevaleciam os nativos do tronco linguístico tupi, subdivididos em diferentes grupos: Tupinambá, Tupiniquim, Tamoio, Caeté, Potiguar, Tabajara etc. Nem sempre eram os nativos que se designavam desse modo, mas assim foram identificados pelos portugueses.

Os nativos de língua tupi chamavam de "tapuias" aqueles que não falavam sua língua. Os tapuias eram minoritários no litoral, e muito numerosos no interior. Falavam línguas dos troncos jê, arawak ou famílias linguísticas menores.
}

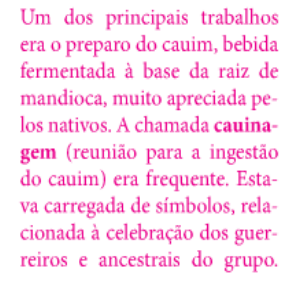

is trabalhos ermenta do baum, bebida mandioca, muito apreciada peos nativos. A chamada cauinaEstacionada à celebração dos guerreiros e ancestrais do grupo.

\section{O cotidiano dos povos tupis}

Os povos tupis viviam em aldeias compostas de cerca de sete ou oito malocas, feitas de palha, talos de madeira e folhas de palmeira. Cada maloca podia abrigar até 100 famílias, de modo que algumas tinham cerca de 600 habitantes. $O$

\section{POVOS INDÍGENAS NO LITORAL DO BRASIL (SÉCULO XV)}

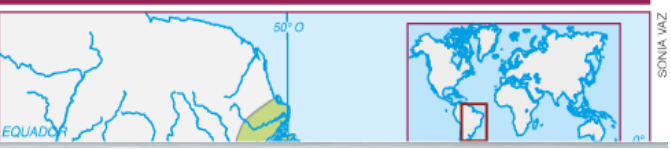

Fonte: VAINFAS et al. (2016, p. 131). 
Figura 3 - imagem retirada do livro de história analisado

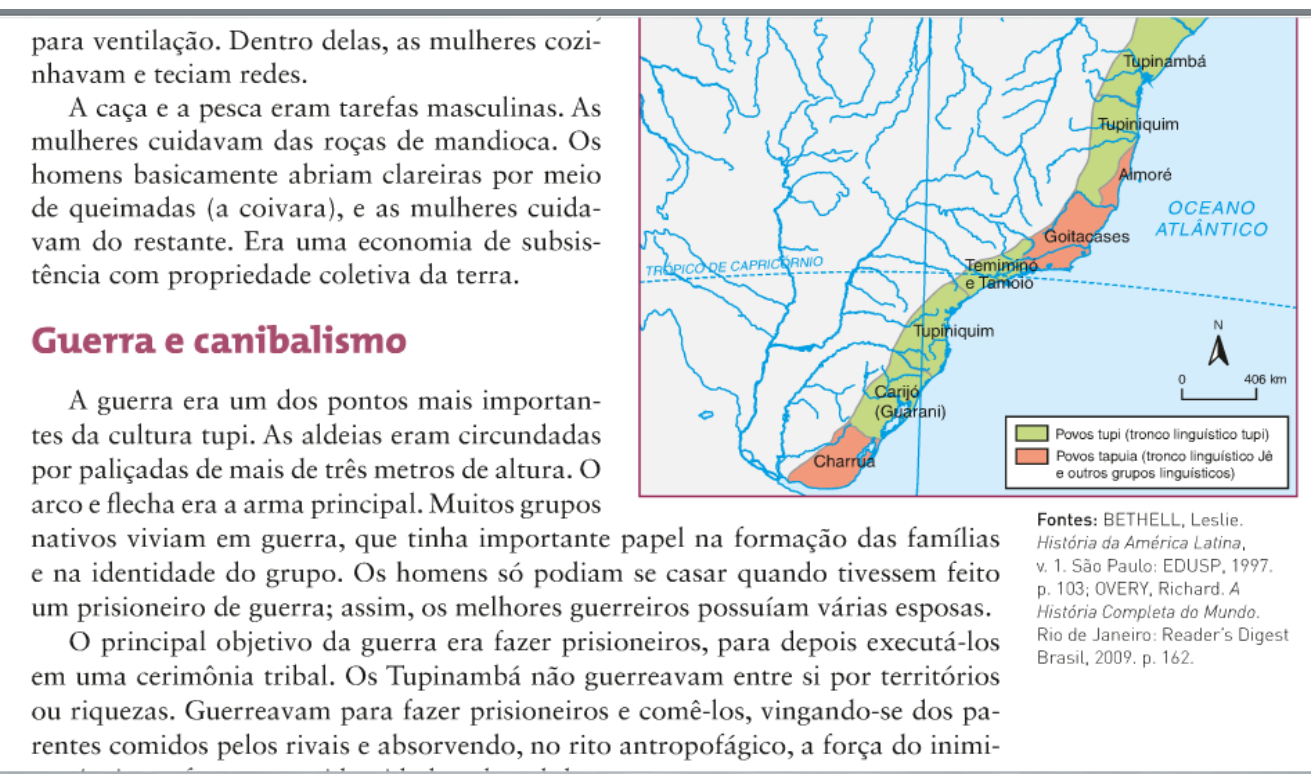

Fonte: VAINFAS et al. (2016, p. 131).

Embora os autores chamem atenção, logo no início do capítulo sobre o processo de nomeação exógeno com as quais os povos originários foram tipificados pelos europeus, dando suporte para se possibilitar uma visão crítica sobre esse procedimento ocorrido em relação às populações que aqui existiam e existem, direcionam o texto para uma simplificação, por ora legitimando e insistindo nessas classificações que reverberam em dicotomias outrora presentes em textos literários do indianismo e fontes documentais do período colonial como: índio doméstico e índio bravo. Para Manoela Carneiro da Cunha (2009) ${ }^{9}$, tais categorias corroboravam para a proliferação no imaginário nacional de etnônimos, como tupis e guaranis (domesticados) e botocudos ou "tapuias"

\footnotetext{
${ }^{9}$ Parte da discussão e comentário é integrante de outro artigo de minha autoria (ROSA, 2015).
} 
(bravos). Aos primeiros eram reservados o direito de integração e o discurso de sua extinção, para os outros restavam o estatuto de fera e a guerra justa.

\begin{abstract}
Para fins práticos, os índios se subdividem, no século XIX, em 'bravos' e 'domésticos ou mansos', terminologia que não deixa dúvidas quanto à ideia subjacente de animalidade e de errância. $\mathrm{A}$ 'domesticação' dos índios supunha, como em séculos anteriores, sua sedentarização em aldeamentos sob o 'suave jugo das leis'. [...] Se essa é a classificação prática e administrativa, há, no entanto, duas categorias de índios que se destacam por outros critérios. Há primeiro, os Tupi e os Guarani, já então virtualmente extintos ou supostamente assimilados, que figuram por excelência na auto-imagem que o Brasil faz de si mesmo. É o índio que aparece como emblema da nova nação em todos os monumentos, alegorias e caricaturas. É o caboclo nacionalista da Bahia, é o índio do romantismo na literatura e na pintura. É o índio bom e, convenientemente, é o índio morto (CUNHA, 2009, p. 61 - 62).
\end{abstract}

A alocação e perpetuação, sem um aparato crítico, aos etnônimos e verbos descritos no livro didático citado, podem levar os discentes a associarem os grupos originários não somente ao discurso da extinção, como potencialmente sucumbirem a simplificações superficiais e caricaturais sobre as culturas e diversidades presentes entre os povos. Associar grupos étnicos ao seu posicionamento geofísico é contraproducente ao objetivo de criticar estereótipos. Como sinaliza Frederick Barth (2011, p. 189-199), importa mais em uma leitura crítica dos processos de nomeação exógenos e endógenos dos grupos étnicos, destacar as relações de interação social dos grupos envolvidos. Segundo Barth:

Os grupos étnicos não são simplesmente ou necessariamente baseados na ocupação de territórios exclusivos. [...]A identificação de outra pessoa pertencente a um grupo étnico implica compartilhamento de critérios de avaliação e julgamento. [...] Assim, a persistência de grupos étnicos em contato implica não apenas critérios e sinais de identificação, mas igualmente uma estruturação da interação que permite a persistência das diferenças culturais (BARTH, 2011, p. 196).

A descrição simplista e acessória sobre o estilo de vida e a produção dos símbolos e signos presentes em cada prática e ritual dos povos originários, como, por exemplo, "a caça e a pesca eram tarefas masculinas"; [...] "os homens basicamente abriam clareiras por meio das queimadas"(VAINFAS et al., 2016, p. 
131.), distancia o discente de entender essa outridade como uma diferença cultural plural e portadora de dinamicidade, vastidão e complexidades próprias, porém também em abertura para o hibridismo cultural. Grupioni (2004) destaca que reduzir as experiências e relações existenciais indígenas a um modelo monológico, às simples contribuições e técnicas na vida na floresta, só revigora o sentido da essencialização, inferioridade e primitividade das culturas indígenas na visão discente.

Ao destacar traços da cultura indígena e incorrer na generalização e simplificação das diversidades pluriétnicas existentes, os manuais didáticos terminam por legitimar e articular categorias conceituais e classificatórias generalizantes como adequadas para o estudo dos povos originários. Tais formulações reforçam a visão de um "índio genérico", estratificado, impossibilitado de conviver em outros meios e ambientes, como o urbano, por exemplo. Apresentados dessa forma nos manuais didáticos, esses discursos reverberam nos discentes as dificuldades de perceber a existência indígena como parte integrante da contemporaneidade e articulada com as perspectivas diversas da própria sociedade em que vivem.

Nessa perspectiva, seria muito mais profícuo nutrir os discentes com noções como o perspectivismo ameríndio para aproximá-los das diferenças e cosmovisões indígenas do que insistir em generalizações estereotipadas e simplistas. Viveiros de Castro $(2002,2015)$ enfatiza o perspectivismo ameríndio como uma proposta ontológica diferencial do mundo ocidental, que não só diverge da tradicional dualidade entre natureza e cultura, como também embaralha todo um conjunto de dualidades metafisicas que orientam a tradição ocidental, tais como objetivo e subjetivo, físico e moral, universal e particular, dado e construído, dentre outros. De acordo com Viveiros de Castro (2002, p. 349), as noções de natureza e cultura em acordo com pensamento ameríndio "[...] não só não subsumem os mesmos conteúdos, como não possuem o mesmo estatuto de seus análogos ocidentais; elas não assinalam regiões do ser, mas antes configurações relacionais, perspectivas móveis, em suma - pontos de vista". 
O desenvolvimento do trabalho em sala de aula, com uma visão crítica que descontrói e pluraliza os discursos sobre as outridades ameríndias, repercute na formação discente aberta ao cuidado e à premissa intercultural na produção de saberes. Embora seja visível a impossibilidade de um tratamento abrangente e mais aprofundado das sociedades indígenas dentro dos objetivos dos manuais didáticos, é preciso munir e "armar" os textos com perspectivas críticas aos conceitos, aos conceitos que explicam os conceitos, e à complexidade que está por trás da construção dos discursos sobre as outridades indígenas. É preciso se distanciar do que o artigo publicado pela primeira vez em $1995^{10}$, de Luis Donisete Grupioni, alertava sobre a visão produzida a respeito dos indígenas nos livros didáticos:

Bom e mau selvagem são imagens opostas e parecem catalisar o imaginário sobre os índios na nossa sociedade. Imagens cristalizadas ao longo de séculos, elas parecem, hoje, revelar algo de concreto e diante delas não se pode ficar indiferente: ou os índios são bons e é preciso que os protejamos tais como eles são; ou os índios são maus e é preciso trazê-los logo à "civilização" (GRUPIONI, 2004, p. 491).

Possivelmente, todos os treze livros didáticos aprovados pelo último PNLD/2018 possuem pontos que podem ser criticados e com abertura para possibilidades de análise em relação à temática indígena. A intenção aqui perpassa muito mais em apontar a necessidade urgente de aliar formação continuada e específica dos quadros docentes para o trabalho crítico com a temática, do que, necessariamente, apontar pela viabilidade ou inviabilidade de um manual. Necessitamos de criticidade do corpo docente, do engajamento de políticas de formação que munam nossos professores e professoras para que usem o livro didático como apoio, mas também como tema de estudo e crítica. É preciso cobrança no que tange às políticas públicas para que os manuais incorporem, de forma mais sistemática e pontual, os estudos recentes de áreas como Antropologia, Filosofia e História no que concerne ao estudo das outridades

\footnotetext{
${ }^{10}$ Notadamente utilizamos a versão do artigo publicada em 2004, na $4^{a}$ edição do livro $A$ temática indígena na escola.
} 
indígenas, assim como o pluralismo e interdisciplinaridade das fontes documentais.

Se é verdade que os manuais desempenham importante papel de suporte e informação no processo de estudo histórico na Educação Básica, também é notável que é preciso formação continuada e vigilância no que concerne ao atendimento da Lei 11.645/2008 na elaboração e escolha desse material didático. Porém, podemos destacar o protagonismo docente na tarefa de implementar a Lei $11.645 / 2008$, que gera atitudes procedimentais no tratamento e articulação curricular na organização das unidades didáticas. Partindo do pressuposto que uma dada imagem sobre os povos originários está sedimentada no imaginário estudantil, a saber, "um" indígena estratificado e impossibilitado de inserir-se e participar ativamente de qualquer projeto da contemporaneidade, é possível colocar em desarranjo tal visão a partir do entendimento de categorias conceituais fundamentais para um estudo crítico da História Indígena como protagonismo e resistência indígena na História.

\section{Referenciais para o estudo do protagonismo indígena nas aulas de História: descontruindo estereótipos}

Embora nos últimos anos na produção acadêmica sobre a História Indígena, de forma geral, tenha havido um avanço significativo na atualização e transdisciplinaridade dos estudos, o produto desses esforços timidamente alcança os espaços da Educação Básica. É importante notar que um dos pressupostos que promovem um avanço de natureza qualitativa sobre os estudos da nova História Indígena é à noção de perspectiva que busca, dentre outros fatores, preponderantemente levar em consideração a interpretação dos próprios indígenas acerca da História (WITTMANN, 2015, p. 17).

Nesse sentido, observamos que um ponto de partida e olhar de natureza crítica aos estereótipos presentes nos manuais didáticos e, quiçá, no próprio imaginário nacional ${ }^{11}$, é desconstruir o viés fatalista, de passado eterno e de

\footnotetext{
${ }^{11}$ A representação de uma imagem sobre os indígenas pode ser alocada como tendo seu início nas crônicas de viajantes europeus e nos próprios textos considerados informativos. Observa-se, pontualmente, uma miríade de regimes de memória e imagem sobre os povos originários no
} 
objeto natural. Sobre este último, observa-se que a inscrição dos indígenas como parte indissociável do que é considerado como "natureza" é um dos estereótipos mais frequentes que se concretiza nos livros didáticos, filmes e, sobretudo, no olhar destinado a estes indivíduos. Muito embora a visão dos indígenas como parte indissociável do ambiente natural possa ser estrategicamente utilizada por grupos indígenas como forma de obter recursos e apoio financeiro de diversos órgãos, tal visão não deixa de ser um estereótipo que nem sempre é benéfico, principalmente em sala de aula. Para Olívio Jekupé (2009), é preciso recusar toda uma gama de identidades, rótulos e estereótipos que alocam os nativos como povos de um passado de cunho essencialista e monolítico, em que os indígenas representam um estágio superado da humanidade e formam um corpo homogêneo e estático no tempo.

É necessário que professores e professoras insistam na desconstrução desses estereótipos, pois sinalizam de forma direta aos discentes a necessidade de pluralizar e dialogar com fontes diversas na escrita e debate sobre a História. Por meio disso, buscamos, nessa parte do artigo, apresentar o conceito de protagonismo indígena como um exemplo profícuo no trabalho em sala de aula, pois sinaliza, também, uma opção de característica metodológica no ensino da História Indígena, a saber, apresentação do conceito; crítica e análise intercultural das possibilidades e limites do conceito; reorganização da memória; e aproximação indiciária com as possíveis respostas.

Destaco que o ponto de partida indiciário, aqui aludido, remete a proposta metodológica e epistemológica do historiador italiano C. Ginzburg (1989), que se caracteriza pela busca dos pequenos indícios, sintomas e especificidades de cada cenário que anteriormente estariam exilados e silenciados em uma dada razão histórica maior, aparecendo como marginalidades historiográficas às quais são comumente conhecidas como Micro História.

Diante de tais pressupostos, surge uma grande dificuldade de natureza conceitual que é a definição do que chamamos de protagonismo indígena. Notadamente nos trabalhos acadêmicos a respeito do tema, se observa um

Brasil. De forma geral, temos uma visão que enaltece a estereotipia típica do romantismo brasileiro; em contraponto a outra, que produz a imagem do "índio aculturado" marcado pela pobreza e miséria. 
recorte temporal e histórico que associa o protagonismo indígena à formação organizada do chamado movimento indígena, por meio das assembleias na década de 1970. Como destaca a historiadora Poliene Soares dos Santos Bicalho (2010), as assembleias indígenas, originadas na década de 1970, são de fato a mola propulsora do movimento indígena no Brasil, pois viabilizaram, de forma inédita, um contato entre diversos povos, como, também, a conquista incipiente de um local de partilha de angústias e resistências.

Porém, para a pesquisadora Graça Graúna (2013), entender o termo protagonismo indígena a partir da ideia de organização, representação e política, ancorados na cosmovisão europeia e nos países que perpetuam a herança do processo civilizatório europeu, é permitir a instalação da armadilha da unilateralidade conceitual. Para a autora supracitada, o protagonismo indígena sempre existiu. Reforçar ou reproduzir um discurso que apregoa o vazio de práticas de resistência, lutas, intercâmbios e relações ocorridas entre os povos originários entre si, e em relação aos invasores europeus, é perpetuar o mesmo discurso que naturaliza uma suposta essência indígena pela negação: "sem fé, sem lei, sem rei". ${ }^{12}$

Considerar as assembleias e as representações políticas indígenas, ocorridas durante as décadas de 1970-1990, como parte indissociável da História e luta dos povos indígenas, não exclui as possibilidades de entender o protagonismo indígena não somente, ou exclusivamente, por meio do contato e relação com o projeto civilizatório europeu ou do projeto de assimilação nacional. ${ }^{13}$ Se faz necessário pluralizar o alcance que tal aposta no termo é capaz de trazer para uma História Indígena intercultural. É preciso desconstruir a ideia de que a História Indígena se limita ao contato com a sociedade ocidental.

Outro imperativo indissociável ao estudo do conceito em sala é o cuidado que ornamenta toda produção e escrita da História. Ou seja, em sala de aula se faz mister que o docente atue criticamente com os discentes salientando que

${ }^{12}$ Essa visão fica claramente projetada na frase de Pero de Magalhães Gândavo no Tratado da Terra do Brasil, em 1573, onde destaca: "A língua deste gentio toda pela costa é uma: carece de três letras - scilicet, não se acha nela $F$, nem $L$, nem $R$, coisa digna de espanto, porque assim não tem Fé, nem Lei, nem Rei; e desta maneira vivem sem Justiça e desordenadamente (GÂNDAVO, 1980, p. 14).

${ }^{13}$ Sobre o paradigma exterminacionista e integracionista projetados como política indigenista no Brasil, ver Munduruku (2012). 
qualquer conceito não representa uma totalidade universal e a-histórica. Trazendo tal percepção ao estudo em pauta, significa destacar os limites do conceito de protagonismo e que ao lançarmos nosso olhar sobre fontes diversas na tentativa de promover uma interpretação do passado, o fazemos utilizando nossos próprios e atuais códigos e sentidos, ancorados em posições do presente. Nesse sentido, cabe observar que destacar o protagonismo indígena na História Indígena não seja, necessariamente, uma simetria com a ideia de "protagonismo" entre os indígenas ou mesmo a ideia de "História", tal como compreendida por nossas categorias conceituais modernas, seja a mesma atribuição de sentido concebida pelos povos originários em diversas fases. É preciso destacar os limites e possibilidades do conceito em questão, percebendo as singularidades envolvidas na perspectiva dos regimes de historicidade entre os povos originários.

Outro equívoco a se evitar é considerar a ação protagonista dos povos originários somente por meio da esfera do enfrentamento às práticas coloniais ou da simples "reação" indígena à ação colonial. Segundo Santos e Felipe (2016, p. 13), tais análises "antes de ser um problema semântico, é um problema epistemológico" que aloca os indígenas e suas motivações em "situações derivadas do contato com o sistema colonial ou do convívio com o homem branco", desconsiderando a possibilidade de uma "lógica interna" e eminentemente criativa, diversa e própria das sociedades ameríndias.

Frente à presença invasiva das populações europeias, na perspectiva dos mais de mil povos que habitavam o espaço posteriormente batizado de "Brasil", o primeiro contato também foi o início de uma gama variada de enfrentamentos, relações e resistências de todas as ordens, que variavam entre o primeiro riso ao modo esdrúxulo com o qual os europeus se vestiam à guerra declarada e sanguinolenta (GRAÚNA, 2013).

Acompanhado desta perspectiva, situa-se um outro estereótipo comum no tratamento da temática do protagonismo, a saber, a construção de um discurso vitimista e fatalista em relação aos povos originários. Tal discurso, segundo Santos e Felipe (2016, p. 18-19), é reforçado com uma tendência historiográfica de reorganizar o discurso histórico com "a voz" dos silenciados, acentuando-se 
com uma narrativa maniqueísta e polarizadora, em que os povos originários eram visibilizados como vítimas estanques do avanço genocida europeu.

Nessa tentativa de pluralizar as posições na historiografia da América indígena se observou uma forte tendência em "substituir o discurso da passividade indígena frente ao avanço colonial pelo da resistência cultural" (SANTOS; FELIPE, 2016, p. 19). Por meio dessa concepção, se propagou uma visão dos povos originários como sujeitos que resistiam de forma impermeável às práticas e influências culturais de ordem externa. Nesse sentido, o conceito de resistência disseminado por essa historiografia repercutiu na formação e reprodução do estereótipo da imobilidade e da pureza cultural dos grupos indígenas. Cabe ressaltar que as concepções sobre a palavra resistência ganharam múltiplas significações, não somente na historiografia, como na Antropologia, Filosofia, Literatura, dentre outras áreas de conhecimento. Em que pese que não se pretende, aqui, fazer uma defesa do termo em seu sentido etimológico ${ }^{14}$, o que sugere uma preocupação para que tais sentidos sejam expressos ou compreendidos como o sentido único e "verdadeiro" da palavra. Os usos e sentidos de um signo (uma palavra) são variáveis no tempo histórico.

É preciso chamar atenção para os sentidos e atributos envolvidos nos usos da palavra por autores indígenas, naquilo que interessa em nossa abordagem. Não temos a presunção de invocar um sentido universal para o termo, ou mesmo desmerecê-lo, enquanto arcabouço conceitual para análise e estudo. Muito embora, a própria historiografia recente dê preferência a conceitos como o de "agência", não é impossível um trabalho profícuo com o termo "protagonismo", se este último vier acompanhado de toda problemática e inquietação que traz o uso de qualquer conceito. Para Maria C. Almeida (2017), o protagonismo indígena se refere a retomada do destaque e da atuação ativa dos variados povos indígenas ao curso da História.

Analisar a documentação, focando os índios e os significados próprios por eles atribuídos aos novos artefatos, relacionamentos,

\footnotetext{
${ }^{14}$ Etimologicamente a palavra "resistência" origina-se do latim, resistentia. Origina-se do verbo resistir (manter firme, persistir, opor repetidamente sem perder a posição), composto de re (intensificação da ação, reiteração ou retorno) e do verbo sistere (estabelecer, tomar posições, assegurar um lugar). Cf: CUNHA, Antonio Geraldo; MELLO SOBRINHO, Cláudio (2015).
} 
condutas e instituições que passavam a fazer parte de seu cotidiano pós-contato, nos leva a compreender os processos de conquista e ocupação da terra de forma mais ampla e complexa. Sem desconsiderar o tamanho da violência contra os índios e as condições desiguais de negociação entre eles e os europeus, podemos observar que, apesar de restritas, suas atuações impuseram uma série de limites aos colonizadores. As narrativas históricas, sem dúvida, se alteram quando incorporamos os índios na condição de protagonistas [...] (ALMEIDA, 2017, p. 20).

Os variados diálogos que a História Indígena vem alavancando com áreas como a Antropologia e Literatura são substanciais para explorar o termo "protagonismo", não apenas como uma adjetivação do tipo que se limita a constatar indícios da presença indígena em variados contextos, até então ainda não vislumbrados por historiadores e historiadoras, mas pensar o protagonismo indígena, e sua exploração em sala de aula, como uma possibilidade de intercalar e agenciar signos e relações de contato que extrapolem e lancem outros desafios aos métodos, fontes e interpretações da historiografia indígena. Se ao estudarmos em sala de aula a História Indígena do período colonial pelo viés do protagonismo indígena, devemos nos munir com a reserva e a perspectiva crítica de estarmos trabalhando com o olhar de um outro sobre o outro, como destacam Santos e Felipe (2016, p. 22), para quem renovar a historiografia indígena perpassa principalmente por "entender que, em situações de contato e convívio, os ocidentais eram os nativos dos índios."

Isso significa lançar o olhar sobre o usufruto e potência metodológica que o termo adquire na contemporaneidade. Para Bicalho (2010), o protagonismo indígena, desde a década de 1970, retoma aspectos da própria afirmação social, ética e política dos povos indígenas, assim como se expande em diversas esferas, tais como: preocupação com a formação escolar diferenciada; organizações representativas e mediadoras organizadas e criadas por povos indígenas; lideranças e intelectuais indígenas em todas as áreas do conhecimento; dentre outras. O termo ganha uma amplitude na atualidade e a possibilidade de agenciar uma perspectiva intercultural no trabalho e ensino da História Indígena na Educação Básica, pluralizando fontes e abordagens; instigando discentes e docentes ao confronto diário dos estereótipos e lugares 
comum da interpretação histórica na possibilidade de um ensino de história posicionado, crítico e investigativo frente aos problemas e desafios da atualidade.

\section{Considerações finais}

Observamos que o desenvolvimento de metodologias e a busca por apoio nos materiais didáticos disponíveis fazem parte do desafio para implementação da Lei 11.645/08, no que se refere ao estudo da História Indígena. Tudo indica que o melhor caminho passa indissociavelmente pelo investimento em políticas públicas que promovam formação continuada para professores em formação e em sala de aula, análise crítica e colaborativa sobre os materiais didáticos, além de uma atuação proativa do docente. A efetivação da Lei 11.645/08 projeta-se em um exercício constante e relacional entre o revisionismo e virada antropológica na historiografia.

No espaço escolar, professores e professoras terminam por se destacar como porta-vozes privilegiados em um debate que transcende os muros da escola e se configura com um imperativo ético, político e social em nossa sociedade. O fato do discurso histórico ser um campo de disputas e de poder, não exclui a abertura de natureza relacional que nos evoca o presente, a saber, o chamado a construir e constituir um viés historiográfico intercultural na Educação Básica, marcado pela compreensão de seus limites, possibilidades e em intenso processo de negociação híbrida, que não busca a supremacia dos regimes de signos históricos de uns sobre os outros. Ao contrário, intenta perscrutar as culturas locais a partir das quais emerge, com o labor colaborativo de produzir memórias históricas e visões sobre elas, um jogo relacional em que uma certa tradição discursiva na historiografia é notadamente hegemônica e seu poder é desigual, porém, nos oferece espaços de negociação e crítica.

Pensar o protagonismo indígena, atrelado à afirmação de ensino de uma História Indígena, é o reconhecimento de um contra discurso que se move no âmbito contrário a uma violência epistêmica que inviabiliza o sujeito indígena e seus próprios regimes históricos, assim como a sua própria experienciação do 
mundo. É como nos ensina uma das possíveis intepretações etimológicas da palavra resistência, retomar um lugar, estabelecer uma posição. É um começo.

\section{Referências}

ADICHIE, Chimamanda. O perigo de uma única história. Tradução de Eria Barbosa. 2009. Disponível em:

http://www.ted.com/tals/lang/ptbr/chimamanda_adichie_the_danger_of_a_singl e_story. html. Acesso em: 15 fev. 2018.

ALMEIDA, Maria Regina Celestino de. A atuação dos indígenas na História do Brasil: revisões historiográficas. Rev. Bras. Hist., São Paulo, v. 37, n. 75, p. 1738, maio 2017. Disponível em:

http://www.scielo.br/scielo.php?script=sci_arttext\&pid=S0102-

$01882017000200017 \&$ Ing=pt\&nrm=iso. Acesso em: 27 jan. 2018.

BARTH, Fredrik. Grupos étnicos e suas fronteiras. In.: POUTIGNAT, Philippe; STREIFF-FENART, Jocelyne. Teorias da etnicidade. São Paulo: Editora da Unesp, 2011. p. 187-227.

BICALHO, Poliene Soares dos Santos. Protagonismo indígena no Brasil: movimento, cidadania e direitos (1970-2009). 2010. Tese (Doutorado em História) -Universidade de Brasília, Brasília, 2010.

BORGES, Jorgeval Andrade. A vez da África?: o ensino da história africana em escolas públicas da Bahia. 2014. Tese (doutorado) - Faculdade de Educação, Universidade Federal da Bahia, Salvador, 2014.

BRASIL. Lei no 11.645, de 10 Março de 2008. Altera a Lei n 9.394, de 20 de dezembro de 1996, modificada pela Lei ${ }^{\circ} 10.639$, de 9 de janeiro de 2003, que estabelece as diretrizes e bases da educação nacional, para incluir no currículo oficial da rede de ensino a obrigatoriedade da temática "História e Cultura AfroBrasileira e Indígena". Brasília, DF: Presidência da República, 2008. Disponível em: http://www.planalto.gov.br/ccivil_03/_ato2007-2010/2008/lei/l11645.htm. Acesso em: 27 jan. 2018.

BRASIL. Guia de Livros didáticos PNLD/2018: história. Brasília: Ministério da Educação: Secretaria de Educação Básica, 2017.

CUNHA, Manuela Carneiro da. Cultura com aspas e outros ensaios. São Paulo: Cosac Naify, 2009.

CUNHA, Antonio Geraldo da; MELLO SOBRINHO, Cláudio. Dicionário etimológico da língua portuguesa. Lexikon Editora Digital, 2015. 
DUSSEL, Enrique. O encobrimento do outro. Petrópolis: Vozes, 1993.

FOUCAULT, Michel. A ordem do discurso. Tradução de Laura Fraga de Almeida Sampaio. 23. ed. São Paulo: Edições Loyola, 2013.

GÂNDAVO, Pero de Magalhães. Tratado da terra do Brasil: história da Província Santa Cruz. Belo Horizonte: Itatiaia, 1980.

GRAÚNA, Graça. Contrapontos da literatura indígena contemporânea no Brasil. Belo Horizonte: Mazza Edições, 2013.

GRUPIONI, Luis Donisete Benzi. Livros didáticos e fontes de informações sobre as sociedades indígenas no Brasil. In: SILVA, Aracy Lopes da; GRUPIONI, Luis Donisete Benzi. (org.). A temática indígena na escola: novos subsídios para professores de $1^{\circ}$ e $2^{\circ}$ graus. $4^{a}$ ed. São Paulo: Global: Brasília: MEC, MARI, UNESCO, 2004. p.481-525.

GINZBURG, Carlo. Mitos, emblemas, sinais: raízes de um paradigma indiciário. São Paulo: Companhia das Letras,1989.

JEKUPÉ, Olívio. Literatura escrita pelos povos indígenas. São Paulo: Scortecci, 2009.

MUNDURUKU, Daniel. O banquete dos deuses. São Paulo: Global Editora, 2009.

MUNDURUKU, Daniel. O caráter educativo do movimento indígena brasileiro (1970-1990). São Paulo: Paulinas, 2012.

ROSA, Francis Mary Soares Correia. A Invenção do Índio. Espaço Ameríndio, Porto Alegre, v. 9, n. 3, p. 257-277, jul./dez. 2015.

SANTOS, Maria Cristina dos; FELIPE, Guilherme Galhegos. Protagonismo como substantivo na História indígena. In: SANTOS, Maria Cristina dos; FELIPE, Guilherme Galhegos. Protagonismo ameríndio de ontem e hoje. Jundiaí: Paco, 2016. p. 13-52.

TEMPO EM CURSO. ano 5, v. 5, n. 2, fev. 2013.

VAINFAS, Ronaldo; FARIA, Sheila de Castro; FERREIRA, Jorge; SANTOS, Georgina dos. História. 3. ed. São Paulo: Saraiva, 2016. v. 1.

VIVEIROS DE CASTRO, Eduardo. A inconstância da alma selvagem. São Paulo: Cosac \& Naify, 2002.

VIVEIROS DE CASTRO, Eduardo. Metafísicas Canibais. São Paulo: Cosaf Naify, 2015. 
WITTMANN, Luisa Tombini. Ensino (d) e história indígena. São Paulo: Autêntica, 2015.

Recebido em 09 de maio de 2018 Aprovado em 06 de fevereiro de 2019 